\title{
Growth, nitrogen fixation, respiration, and anitrogen budget for cultures of a cosmopolitan diazotrophic endosymbiont (Teredinibacter turnerae) of shipworms - ERRATUM
}

\author{
R.E.A. HORAK AND J.P. MONTOYA
}

doi:10.1017/Soo25315413001483, published by Cambridge University Press, 7 November 2013

The title of the article (Horak and Montoya 2013) is corrected as follows: 'Growth, nitrogen fixation, respiration, and a nitrogen budget for cultures of a cosmopolitan diazotrophic endosymbiont (Teredinibacter turnerae) of shipworms'

\section{REFERENCE}

Horak R.E.A. and Montoya J.P. (2013) Growth, nitrogen fixation, respiration, and a nitrogen budget for cultures of a cosmopolitan diazotrophic endosymbiont (Teredinibacter turnerae) of shipworms. Journal of the Marine Biological Association of the United Kingdom. doi:10.1017/ Soo25315413001483 